\title{
SOBRE LA ESPERANZA
}

Benito José Peral Ríos ${ }^{1}$

DOI: https://doi.org/10.52039/seminarios.v55i192.494

La esperanza es virtud de lucha. Desde los contenidos interiores que señala el autor hay todo un proceso de llegada a la tierra que necesita la arada. Por eso la esperanza es motor de nuestro compromiso comunitario y social.

El autor enmarca la descripción de la esperanza en el ámbito más amplio, es todo el horizonte, de la felicidad. Una cuestión que nos atañe en esta revista de teología y pastoral de las vocaciones. Porque el descubrimiento de la propia felicidad, experiencia, vivencia y proyecto (pasado, presente y futuro), es ni más ni menos que el avistamiento de la propia vocación-misión.

La Providencia, ese dedo de Dios sobre el mundo como dice el autor, señala de manera casi inefable nuestro lugar, nuestro camino, nuestra meta inalcanzable, la sabiduría del corazón. Y nosotros vamos tras la huellas de la Vida?2.

1 Médico Psiquiatra. Malagueño, esposo de Trini, tienen dos hijos y muchos amigos. El director de esta revista se considera hermano y amigo del autor. Hizo sus estudios en la Universidad de Navarra, trabajó en el hospital de san Juan de Dios de Ciempozuelos y ejerció la docencia en la Universidad Pontifica de Comillas. Actualmente tiene consulta en Madrid. Ha publicado diversos trabajos. Destacamos el último libro aparecido: Luz más luz, Desclée de Brouwer, 2004.

2 El trabajo que les presentamos es una conferencia pronunciada por el autor en Badajoz, el 20 de noviembre, 2008, en la semana de teología que organiza la arzobispado de Mérida-Badajoz todos los años. 
Introducción, (48); 1. Citas, (48); 2. Distintas concepciones, (50); 2.1. Pasividad, resignación, (50); 2.2. Tener anhelos por satisfacer deseos y llenar carencias, (51); 3. El núcleo de la esperanza (52); 3.1. Temporalidad comprometida de futuro, (52); 3.2. Contar con el corazón, (54); 3.3. Vivir en confianza (57).

\section{INTRODUCCIÓN}

Como psiquiatra cabría esperar que les hablara de la desesperanza desde el punto de vista psicopatológico. Lo haré, pero no me extenderé en ello, no vaya a ser que la liemos.

Además de psiquiatra soy, gracias a Dios, otras cosas. Por lo pronto una duda con patas y por lo tanto, quizás no sea el más indicado para hablarles de la esperanza como virtud teologal, aunque algo diremos. Doctores tiene la Iglesia.

Voy a intentar hablarles de la esperanza como actitud básica en la vida. De la esperanza en relación con la felicidad. Y deseo lograr transmitirles algo positivo, algo que a mí al prepararlo y a ustedes al escucharlo nos acerque un poquito a la sabiduría de vida.

Hablar de esperanza es hablar más desde el corazón que desde la razón. No esperen de esta conferencia un riguroso estudio lleno de argumentos lógicos y racionalmente contundentes. No sé si podría hacerlo, pero sí sé que no quiero hacerlo. Así que espero, tengo la esperanza, que sea cierto aquello que alguien dijo: Lo que sale del alma al alma llega.

\section{CITAS}

Voy a iniciar la exposición con algunas citas, unas de filósofos influyentes, otras de personajes insignes, pero también de poetas y de libros sagrados. Les resultará contradictoria, porque verán cómo para algunos la esperanza es algo muy positivo, mientras para otros es muy negativo.

- En el Mahabbarata, el libro de la espiritualidad hindú se puede leer: Sólo es feliz el que ha perdido toda esperanza, pues la esperanza es la mayor tortura y la desesperación la mayor felicidad.

- Nietsche, un filósofo tan influyente como desesperado, decía: La esperanza es, en verdad, el peor de los males, porque prolonga las torturas de los hombres.

- Schopenhauer, un viejo cascarrabias, tremendamente pesimista, 
misógino como Nietsche, y por cierto los dos solteros aunque hay que reconocerle que pocos filósofos escriben tan bien como él, tenía también una visión negativa de la esperanza, todo pesimista tendrá una visión pesimista de la esperanza, decía: Quien ha perdido la esperanza ha perdido también el miedo: tal significa la palabra desesperado.

- André Comte-Sponville, un filósofo actual muy leído en Francia, ha escrito un libro titulado La felicidad, desesperadamente en el que podemos leer: La esperanza es un deseo referido a lo que no tenemos, del que ignoramos si será o no satisfecho y cuya realización no depende de nosotros... La esperanza es por lo tanto, desear sin gozar, sin saber y sin poder, es en definitiva un mal, una trampa para la felicidad.

- Alexander Pope, un filósofo y poeta británico del dieciocho: Bienaventurado el que nada espera, porque nunca sufrirá desengaños.

- Para Don Miguel de Unamuno, también filósofo y poeta, mucho más conocido por nosotros, que como cabe esperar ve en la esperanza un camino para la salvación que le liberase de su tan temida Nada, nos advertía: Espera, que sólo el que espera vive. Pero teme el día en que se te conviertan en recuerdo las esperanzas.

- Rosalía de Castro. A veces los poetas dicen más que los filósofos y además lo dicen estéticamente:

Quien contempla la ilusión

de su esperanza soñada

muriendo en el corazón

al grito de la razón,

¿qué es lo que le queda?...jNada!

- Oscar Wilde: Todos vivimos en el cieno, pero algunos levantamos los ojos hacia el cielo.

- Para Descartes, el filósofo con el que se inicia la filosofía moderna, la esperanza nos instala en la perspectiva de la adquisición de algo que es positivo para nosotros, y con opciones de lograrlo.

- Para Tales de Mileto, el primero de los filósofos: La esperanza es el único bien común a todos los hombres; los que todo lo han perdido la poseen aún. Es decir que lo último que se pierde es la esperanza.

- Y la famosa frase: Mientras hay vida hay esperanza, se debe a Teócrito, un poeta griego del siglo tercero antes de Cristo, que influyó en el gran Virgilio. 


\section{DISTINTAS CONCEPCIONES}

Pareciera que hay pues una concepción positiva de la esperanza y otra negativa. Intentemos aclararlo.

\subsection{Pasividad, resignación}

Es cuando la esperanza supone pasividad o resignación, es decir, si creemos que no hay nada que hacer en este valle de lágrimas y lo único que nos queda es esperar la otra vida, el Reino. Dice un teólogo amigo mío que la resignación no es cristiana y que es en este mundo, lleno de dolor y sufrimiento, donde debemos trabajar por el Reino, aún a sabiendas que como el horizonte nunca lo alcanzaremos. Por cierto, en el Reino ya no habrá ni fe, ni esperanza, porque como dicen Santo Tomás y San Agustín, ya no habrá esperanza porque no habrá nada que esperar, no habrá fe porque estaremos ante Dios, no habrá más que Amor y Verdad. Lo que pone Dante en la puerta del infierno, estaría casi mejor en la puerta del paraíso: Perded toda esperanza al traspasarme.

Los estoicos también consideraban la pasividad como un mal, de hecho consideraban la esperanza como una pasión, una debilidad y no como una virtud, una fuerza. Así hay que entender la sentencia de Séneca en las cartas a Lucilio: Cuando desaprendas a esperar te enseñaré a querer.

Una esperanza pasiva y resignada no es por lo visto ni estoica ni cristiana, y desde luego no es psicológicamente sana. Otra cosa muy distinta a la resignación y que sí es psicológicamente sana es la capacidad para asumir. En la oración de la sabiduría, una de las más bellas que conozco, encontramos la clave para no confundir la pasividad y la resignación con el asumir: Dios mío, dame fuerzas para resolver aquellos problemas que tienen solución; dame paciencia para asumir aquellos problemas que no tienen solución; y dame inteligencia para saber diferenciarlos.

La esperanza ha de ser activa y luchadora. Pondré un ejemplo del ámbito de la política que todos entenderéis. Me tengo por ser bastante tolerante, no es ningún mérito, lo exige mi profesión, pero les confieso que hay dos cosas que detesto profundamente, una es el racismo y la otra cualquier tipo de nacionalismo. Tengo la esperanza de que algún día desaparezcan todas las banderas (o que sólo quede una blanca que tenga por patria ninguna nación) y tengo la esperanza que también se borren todas las fronteras que son obstáculos para el crecimiento armónico y justo de la humanidad. Si algún partido político defendiera este principio, yo estaría de acuerdo. Pero mi grado de implicación podría ser muy distinto; podría ser un simple votante 
que se acerca a las urnas cada cuatro años para depositar su voto para ese partido; podría ser un simpatizante que acude a las convocatorias y a los mítines; o podría ser un afiliado y activo militante que más que implicado estuviera comprometido. Mi amigo Juanjo García para distinguir entre estar implicado y estar comprometido, dice que en un par de huevos fritos la gallina está implicada y que en un chorizo el cerdo está comprometido. Pues bien, en esto de la esperanza no basta con esperar, ni siquiera basta con implicarse, hay que comprometerse, hay que mojarse o aún más, hay que mancharse.

\subsection{Tener anhelos por satisfacer deseos y llenar carencias}

Hay muchas personas que creen que la felicidad consiste en tener lo que se desea. Ésa es de hecho la concepción de la felicidad para uno de los más grandes filósofos, Platón. Pero notemos que deseamos lo que no tenemos y por lo tanto, todo deseo supone una carencia. En efecto, todo deseo es señal de una ausencia, de una falta, de un vacío. Cuando lo satisfacemos, la dicha nos dura muy poco y enseguida surge de nuevo otra necesidad, otro deseo. Ya decía Epicuro que todo deseo satisfecho crea deseos nuevos y multiplica el sentimiento de frustración. Cuando conseguimos lo que hemos estado persiguiendo durante mucho tiempo, comprobamos que no es tanta la dicha, que el placer que obtenemos es mucho menor que el esperado. Cuando alcanzamos esa dicha por largo tiempo esperada, apenas nos sentimos más contentos, ni más alegres, pasados los primeros instantes. Dicen por eso que lo malo de desear mucho una cosa, es que acabas consiguiéndola, y la posesión mata el deseo, y con la satisfacción cesa el placer.

Es como un pozo sin fondo, que por momentos parece llenarse y rebosar, pero no, su estar lleno es muy efímero y rápidamente vuelve la falta, la oquedad. $Y$ no se trata de seguir inútilmente rellenando lo irrellenable, se trata de renunciar al lleno, de aceptar la incompletud (Lacan). Se trata de percatarse de la trampa, la trampa es considerar que ser feliz es tener lo que se desea. Porque si esto es así, no habrá manera de ser felices. Iremos de deseo en deseo, en una huída hacia delante. Pondré un ejemplo: Todos sabemos que el paro es una desgracia. Es carencia, ausencia, sufrimiento. El parado que quiera trabajar se dice: ¡Qué feliz sería si tuviera trabajo! Pero esto sólo es válido para el parado, porque el que está trabajando con demasiada frecuencia siente que el trabajo es un tripalium y se dice: ¡Qué feliz sería si me tocara la lotería y pudiera dejar el trabajo! Es como la vista, que sólo garantiza la felicidad para un ciego.

Que Platón me perdone pero ser feliz no puede ser tener lo que se desea, sino disfrutar de lo que se tiene. El hombre más feliz que yo he conocido, ya 
murió, era Diego el de los 'iguales', el ciego que vendía los cupones de la ONCE en mi pueblo hace años. Era un hombre sencillo, para mayor desgracia no nació ciego, perdió la vista en la guerra en una explosión (recuerden la canción de Serrat: No hay nada más bello que lo que nunca he tenido, nada más amargo que lo que perdí. Serrat aquí se nos muestra platónico, pero nada de eso iba con Diego). Diego era soltero y vivía con su hermano oligofrénico en una casita muy humilde en el barrio más humilde. Pero siempre estaba contento, siempre sonreía, cuando me acercaba a él y me reconocía por la voz, su cara se iluminaba de alegría y me saludaba y me hablaba del calorcito que sentía con el sol, o de lo a gusto que se encontraba sintiendo como llovía, o lo ilusionado que estaba con la llegada de la Semana Santa y que se pondría su túnica morada para ir agarrado al paso de Jesús Nazareno. Jamás le vi triste.

Tener esperanza será algo negativo si supone tener anhelos por satisfacer deseos y llenar carencias. Pero la auténtica esperanza no es deseo por tener, sino afán por alcanzar la autorrealización. Tiene mucho más que ver con el ser que con el tener. Y sólo a esta clase de expectativa cabe llamarla esperanza.

\section{EL NÚCLEO DE LA ESPERANZA}

\subsection{Temporalidad comprometida de futuro}

Para desarrollar este punto precisamos algunos conceptos previos sobre el tiempo. Aunque no sepamos definirlo, sabemos qué es. Todos somos, de alguna manera, tiempo. Notamos cómo pasa por nosotros o nosotros por él, que no es lo mismo pero es igual. Lo dividimos en pasado, presente y futuro. $\mathrm{Y}$, sin embargo, lo único que existe es el presente. El pasado ya no es, ni nunca fue porque cuando fue, fue presente. El pasado es memoria, memoria presente de lo pasado, recuerdo. Y en cuanto al futuro podemos decir que tampoco existe, porque aún no es, ni será porque cuando sea será presente, el futuro es expectativa, expectativa presente de lo futuro, angustia, miedo o espera, esperanza.

Pero aunque sólo existe el presente, la mayoría nos empeñamos en no vivir en él. Solemos estar unas veces mirando hacia atrás, en el pasado; y otras mirando a lo lejos, en el futuro. Mirar al pasado nos lleva a la melancolía; el depresivo, decimos los psiquiatras, tiene una temporalidad de pasado. La mujer de Lot que mira hacia atrás y se convierte en estatua de sal es la figura bíblica de lo que les digo. Mirar al futuro nos lleva a la ansiedad, cuando no a la angustia; porque el futuro siempre es incierto, y es ahí donde vive el 
paciente ansioso. Hay incluso personas que viven tanto en el pasado como en el futuro, están a la vez ansiosos y deprimidos.

Sólo los que son capaces de situarse en el presente, de disfrutar del momento, son felices. Lo vieron los clásicos, que hablaban del Carpe Diem; y lo ha visto siempre la filosofía oriental, todas las técnicas de meditación se encaminan a ello. Los niños pequeños, incapaces aún de construir los sectores de la temporalidad, son felices porque viven en el presente. Cuando van creciendo, comienza el engaño. Abandonan paulatinamente el paraíso del presente y se escapan hacia el futuro. Les asignamos identidad: ellos son el futuro.

Los ancianos son el pasado y allí suelen habitar. Sin apenas futuro, vegetan recordando sus tiempos, como si este tiempo, el ahora, no les perteneciera. ¿Cuándo nos daremos cuenta de que todo es una trampa, que no hay ningún día llamado mañana, que hoy es siempre todavía, que el tiempo es un invento de Satanás? Lo de que no hay ningún día llamado mañana, me lo enseñó de verdad mi hijo Benito...

La esperanza será negativa y será una trampa que nos aleja de la felicidad si nos lleva a una temporalidad predominante de futuro. Porque nos alejará de vivir el presente y disfrutar de las pequeñas y grandes cosas que tenemos en el aquí y ahora. $Y$ que pasan desapercibidas cuando no prestamos atención a lo vivido en el presente. Respirar, Beber, Oír, Ver... Sólo cuando carecemos de ello lo valoramos. Valorar lo que tenemos y disfrutar de lo que tenemos es algo que se hace en el presente, prestando atención al aquí y ahora. La manera más sana de vivir es teniendo una temporalidad de presente, dando vida a los días y no acumulando días de vida. Hay vidas cortas cargadas de vida y vidas largas sin vida apenas.

Además seguro que se han dado cuenta que la vida es muy corta por muy larga que sea. El tiempo subjetivo, el tiempo vivenciado, la vivencia subjetiva del transcurso del tiempo, es como un movimiento uniformemente acelerado. A medida que somos más mayores el tiempo se acelera. Cuando éramos niños los días eran larguísimos y no digamos las semanas o los meses. Cuando vamos creciendo el transcurso del tiempo se va acelerando y los años pasan enseguida. Dice mi suegro que ya apunta hacia los ochenta que de la última década ni se ha enterado. El poeta cántabro, Jorge Guillén sólo precisa tres versos para transmitirnos esta idea:

Y se me escapa la vida,

ganando velocidad

como piedra en su caída.

Pero tener una temporalidad fundamentalmente de presente no significa vivir atado a la estaca del presente, sin tener en cuenta la historia, 
la experiencia, la memoria presente de lo pasado. Para la madurez psicológica se precisa la experiencia del pasado y también tener un proyecto de futuro, un proyecto de vida estable. Es aquí donde una esperanza sana interviene positivamente, apuntando al individuo hacia una meta, hacia un horizonte. La persona que carece de proyecto alguno se siente perdida y desubicada. Como un velero en medio del océano, sin rumbo fijo, sin cuaderno de bitácora y sin timón. No hay ningún viento favorable para un barco que no sabe a qué puerto arrivar. La esperanza será positiva si nos aporta un proyecto de vida sano. Éste debe favorecer el desarrollo de nuestro ser, facilitar nuestro crecimiento como personas, hacernos mejores. Una vida así es como una vela encendida que mientras se va gastando va llevando a cabo su fin que es dar luz y calor a los que alumbra, una vela que mientras se va consumiendo se va consumando.

Resumiendo lo dicho hasta aquí: La esperanza será algo negativo si es pasividad y resignación, si es deseo de tener lo que me falta y si es habitar en el futuro perdiendo el presente. Pero la esperanza será positiva si es compromiso con un ideal, si es trabajar por ser mejores, si es contar con un proyecto de vida, con un horizonte vital. Una esperanza así nos acerca a la felicidad verdadera, que no es diversión, ni evasión, ni consumismo. La verdadera felicidad está inexorablemente ligada a la sabiduría de vida y ésta a la virtud.

\subsection{Contar con el corazón}

Quiero detenerme ahora en otro aspecto de la esperanza que personalmente me resulta fundamental. Creo que tener esperanza supone no contar sólo con la razón, sino también con el corazón. Aristóteles, en un mal día, definió al hombre como animal racional. Cada vez tengo más claro que lo más característico del ser humano y de su psiquismo es su condición de animal sentimental.

Los sentimientos, en todas sus formas, motivan más nuestra conducta que la razón. Por eso el sentencioso Pascal decía que el corazón tiene razones que la razón no comprende.

Una vieja clasificación de los sentimientos distinguía entre sentimientos sensoriales, vitales, psíquicos y espirituales. Los sentimientos sensoriales estarían a medio camino entre la sensación y el sentimiento, estarían localizados en el cuerpo pero serían algo más que una simple percepción, el ejemplo sería el dolor físico. Los sentimientos vitales tendrían también una repercusión somática pero no localizada sino difusa, un ejemplo sería el aplanamiento, el cansancio. Los sentimientos psíquicos se vivencian 
desvinculados casi por completo de lo somático, serían una manera de estar psicológicamente motivados por algo o alguien que nos pone en marcha. Sentimientos de esta naturaleza serían la alegría, la tristeza y un sinfín más. Por último, los sentimientos espirituales serían más que formas de estar, maneras de ser. Decimos estoy contento y soy feliz, estar contento sería sentimiento psíquico, mientras que ser feliz sería sentimiento espiritual. Los sentimientos espirituales son mucho más estables y de carácter no circunstancial sino absoluto. La esperanza sería en este sentido un sentimiento espiritual. $\mathrm{Y}$ por ello nos topamos ahora con la vertiente trascendental de la esperanza que tiene en última instancia que ver con el sentido de la existencia y de nuestra existencia.

Puede parecer que me estoy saliendo del tema de la esperanza y que estoy tratando un tema distinto que es el de la fe. Pero no es así. La fe y la esperanza son casi la misma cosa. Decía San Pablo que la fe es la sustancia de las cosas que se esperan.

El hombre reclama respuestas a preguntas como ¿quién soy? o ¿qué sentido tiene mi existencia? y esas respuestas no han llegado ni pueden llegar, en mi opinión, de la razón, de la ciencia. La ciencia es pensamiento racional y con ella el hombre ha logrado avances médicos y tecnológicos que le han permitido mejorar extraordinariamente sus condiciones de vida. Pero la ciencia, aunque lo intenta, no puede dar contestación satisfactoria a los grandes interrogantes que de una forma $u$ otra en su interior el hombre se hace. La razón no basta, la razón no es suficiente, el ser humano cuenta en su psiquismo con una parte no racional que se nutre de creencias. El ser humano tiene, como ustedes saben y perciben, muchas necesidades de distinta índole, unas son físicas, como el comer o el beber y otras son metafísicas y entre ellas está la necesidad de creer, o lo que es lo mismo, la necesidad de esperar, la necesidad de tener esperanza.

¿Por qué hay gente que llama a Rappel? ¿Por qué proliferan tanto en una sociedad como la nuestra los videntes, los futurólogos, los expertos en tarot y similares? A primera vista puede parecer un contrasentido que estando como estamos en plena era científica se den estos fenómenos. A mí, sin embargo, no me parece nada extraño. Creo que este fenómeno denota la necesidad que existe en nuestra sociedad de creer, de esperar, de esperanza. Cuando las creencias son aportadas por la religión hablamos de fe, cuando las creencias no están vinculadas con la religión hablamos de magia. Y cuando la religión está en declive prolifera la magia, es decir Rappel y compañía. Creo que en nuestra sociedad hay una crisis de creencias, la religión por motivos muy complejos de analizar ha perdido seguidores y eso condiciona que unos busquen en la magia y otros hagan de la ciencia una religión. 
Pero no es lo mismo tener una religión mágica o tener como religión a la ciencia o tener una u otra religión de las muchas que existen y que existieron. La influencia que la religión tiene en la psicología de un pueblo y por lo tanto en la psicología de cada individuo es extraordinaria. La manera de percibir la vida, la forma de estar en el mundo, la visión que tengo de mí mismo y de los demás, van a estar muy condicionadas por la concepción religiosa, por la imagen de Dios que tenga cada sociedad.

En la Grecia clásica los dioses formaban una especie de club situado en el piso de arriba. Eran unos dioses muy humanos con los que no resultaba difícil llegar a acuerdos. Muy distinta era la situación en la sociedad azteca de la era precolombina. Sus dioses padecían una especie de insaciable hemofilia y exigían corazones sangrantes para calmar su furia. Me contaron en una visita a Teotihuacan (me encantaría saber que no es cierto), que a una divinidad encargada de la lluvia (quizá fuera Quetzalcóalt, la serpiente emplumada) había que contentarla con sacrificios humanos de recién nacidos. Vivir para los pobres aztecas con semejantes dioses debía ser un vivir muy distinto que el de los griegos con Zeus, Afrodita y compañía. Y desde luego, muy distinto también al de un cristiano. Hay un cuadro bellísimo y conmovedor de Rembrandt en el museo Hermitage de San Petersburgo que se llama El Regreso del Hijo Pródigo. Sólo lo he visto en reproducciones y he leído un libro maravilloso sobre él. Transmite la esencia de la parábola de Cristo: Dios es un padre, lleno de amor compasivo, que acoge, abraza y perdona a su hijo pródigo. La manera de vivir cuando se tiene la esperanza puesta en un Dios que es amor y perdón es sin duda muy distinta a la que se tiene si uno cree o espera a un Dios caprichoso, justiciero o vengativo.

En nuestra sociedad, decía antes, hay una crisis religiosa y muchos buscan en la ciencia la respuesta a los grandes interrogantes. Muchos científicos y muchas personas que tienen puestas sus esperanzas en la ciencia se confiesan ateos, no creyentes. Pareciera que en ellos no existe la necesidad de creer, pero claro que creen. Creen por lo pronto en la razón como único camino hacia la verdad y creen en el azar. Aunque cabría pensar lo contrario la ciencia rigurosa, la ciencia que sólo cree en la razón, que sólo cree en sí misma, desde Galileo para acá, cree, paradójicamente, en el azar. Es verdad que descubren leyes, fórmulas y ecuaciones que explican desde el movimiento de los astros hasta la sucesión de cualquier fenómeno, pero niegan que detrás de todo ello haya alguna intencionalidad. La evolución de la vida y de las especies la explican por cambios y mutaciones que traen consigo mejor adaptación al medio. Pero las mutaciones son producto del azar y detrás de ellas no hay para la ciencia finalidad alguna.

Yo, por mi parte, creo que el azar no existe. Pienso o mejor creo o mejor aún quiero creer, es decir tengo la esperanza, que todo lo que acontece, que todo lo que nos ocurre y que nosotros mismos no somos producto del azar. En lo 
grande y en lo pequeño, en lo extraordinario y en lo cotidiano, en lo físico y en lo psicológico, en la naturaleza y en la sociedad, en todo advierto, intuyo o barrunto una Voluntad oculta. Esa Voluntad toma a veces forma de ley física que podemos determinar con la ciencia; otras veces toma la forma de motivo psicológico que podemos comprender; otras muchas permanece para nosotros oculta y entonces lo llamamos azar. Pero el azar, como dijo ese genio del ingenio que fue Borges, es el nombre que nuestra inevitable ignorancia da al tejido infinito de causas y efectos. $Y$ creo que no se vive de la misma manera si uno piensa que es fruto del azar, una feliz o desgraciada coincidencia, una chispa fugaz y aleatoria de vida en un universo sin sentido; que fruto de una Voluntad, con un propósito, una intención y con un fin. Yo soy hijo de mis padres, nací por amor y no por azar, todo lo que hago y no hago, digo y callo tiene un porqué. No quiero creer en la suerte y sí en la Providencia, que es el dedo de Dios cuando quiere permanecer en el anonimato.

Esperar o Desesperar, ésa es la cuestión. Alguien podrá decir y con razón que ninguna de estas creencias que acabo de expresar son contrastables o verificables, por supuesto que no, ni falta que hace, la esperanza no está hecha de razón sino de corazón. Ya ven me he ido deslizando desde la vertiente psicológica a la vertiente trascendental de la esperanza. Martín Descalzo, sin nombrarla, describía poéticamente la Esperanza en su vertiente trascendente de una manera conmovedora, decía: Morir es acabar de llorar y hacer preguntas; ver al Amor sin enigmas ni espejos; hallar dejando los dolores lejos, la Noche-luz tras tanta noche oscura.

\subsection{Vivir en confianza}

Para Santo Tomás de Aquino tres son las virtudes que llama teologales: la fe, la esperanza, y la caridad. Las tres están muy relacionadas entre sí. Como virtudes teologales que son, son dones que Dios dona. Pero en el orden no trascendente, sino psicológico, las tres tienen relación con sendas necesidades psicológicas, esenciales para una vida plena, para una vida sana: necesidad de creer, necesidad de amar, necesidad de esperar $Y$ estas tres necesidades tienen como denominador común algo básico, algo que en mi opinión es esencial para un psiquismo sano, algo sin lo cual esta vida es un infierno, me estoy refiriendo a la confianza. Creer es confiar; Esperanza es confiar; y el amor que es la necesidad de salir de uno mismo, es también confiar.

Todas las relaciones humanas positivas se sustentan en la confianza, es una especie de garantía. Así es en todos los ámbitos, en la familia donde todos hemos crecido bajo el cielo protector de unos padres generosos en los que 
confiamos; y en la sociedad en la que vivimos confiando en valores supremos como la justicia. Así es en la relación amorosa en la que exigimos fidelidad para que permanezca la confianza. Y así es en la amistad, esa forma de amor tan libre, cuyo rasgo esencial es también la confianza.

En el psiquismo humano, la falta de confianza -la desconfianza- genera problemas psicológicos que van desde la simple inseguridad hasta el paranoidismo más enfermizo. El paranoide es el que desconfía sistemáticamente de todos, el que ve en el otro a un enemigo potencial, el que interpreta las acciones de los demás como deliberadamente hostiles hacia él. Vive en alerta continua, con los ojos y los oídos muy abiertos, siempre en guardia, con la mosca detrás de la oreja. En los casos más extremos todo está cargado de oscuras sospechas amenazantes, de segundas intenciones, de doble sentido, nada es lo que parece. Muchas personas paranoides fueron un día niños privados de una atmósfera de confianza.

Una pareja de verdad es mucho más que un simple dúo, es amor y duración. Algo tan valioso no puede estar fundamentado sólo en la pasión, tan efímera y que siempre declina. Es la confianza mutua la que da solidez a la pareja. $Y$ es el engaño, la infidelidad, lo que hace que salte añicos. Cuando falta la confianza surgen también los celos, un sentimiento atroz que daña siempre a ambos y que a veces llega a extremos terribles.

Podemos practicar la confianza en los demás negando ese maldito y triste refrán del piensa mal y acertarás. Es preferible confiar en los demás, aún a sabiendas que en algunas ocasiones quedaremos defraudados, que vivir instalados en el infierno de la desconfianza.

Pero la confianza tiene otra vertiente que es esencial para poder disfrutar de la vida, me refiero a tener confianza en uno mismo, sentirse seguro, valioso, capaz. Una persona así no utiliza máscaras intentado aparentar lo que no es, vive en la autenticidad, sin dobleces. No se siente ni superior ni inferior, sencillamente porque no se compara. Vive en el presente, sin nostalgias, asumiendo el pasado y sin estar excesivamente preocupado por el futuro. Se siente satisfecho de sí mismo. Tiene un sistema de valores y vive en consonancia con él, pero es flexible, evoluciona, está abierto al cambio y al crecimiento.

La confianza es certeza y convencimiento que nos aportan seguridad. Es tener fe en uno mismo, en los demás y en la vida en general. Confiar es creer que uno no va a ser engañado, ni traicionado. Un niño pequeño precisa para su desarrollo integral de muchas cosas y entre ellas está la confianza. Sólo con ella crecerá sin miedos y sin angustias excesivas. Sólo así podrá tener una infancia feliz y podrá llegar a ser un adulto seguro. En el psiquismo humano, la falta de confianza -la desconfianza- genera problemas 
psicológicos que van desde la simple inseguridad hasta la angustia más extrema.

La esperanza es confianza y supone optimismo, incluso en los periodos de dolor y sufrimiento. Porque si estoy en la esperanza, cada fracaso, cada crisis es una oportunidad para el crecimiento espiritual. Alguien, no sé quién, qué más da, dijo que nadie se eleva sin pasar por el fuego del sufrimiento. La esperanza es para mí aquello que viene a socorrerme cuando percibo con toda crudeza lo dura que es la vida. La esperanza es creer más en la fuerza del amor que en la del odio, más en la fusión que en la fisión. La esperanza es confiar en que a pesar de todo el Espíritu nunca marra, ni juega a los dados. La esperanza es creer que todo es Providencia, que al final todo encaja, que los opuestos son complementarios, que todo sucede para mejor, que el bien que es el amor está en las entrañas del universo y de su misterio. 